\title{
Investigation of failure mechanisms in ion irradiated X-750 Ni-based superalloy using transmission electron microscopy
}

Zhongwen Yao ${ }^{1}$ and Pooyan Changizian ${ }^{2}$

${ }^{1}$ Queen's University, Kingston, United States, ${ }^{2}$ Queen's University, United States

X-750 Ni-based superalloy is used as garter spring spacer material in the fuel channels of the CANada Deuterium Uranium (CANDU) reactors due to their excellent mechanical and corrosion properties, where nano-size $\gamma^{\prime}$ particles with ordered structure and coherent interface are responsible for a such high strength. However the component exhibits significant embrittlement after a long term service due to neutron radiation in the nuclear reactors [1]. In the current study the energetic helium-ion implantation was employed to emulate the after-service microstructure, coupled with advanced TEM analysis to investigate the deformation and fracture mechanisms via crack initiationlpropagation in the alloy. Our previous work confirmed that high temperature helium implantation created a high density of cavities in the microstructure as figure 1 indicated, which is very similar to that of neutron irradiated material [2]. Smallspecimen tensile tests have been carried out which showed significant ductility loss for He-implanted X750 compared to as-received material. The deformation mechanism in X-750 alloy was found to be planar slip which resulted in the formation of narrow slip bands. This was attributed to the low stacking fault energy of X-750 alloy as well as the possible shearing of a high density of ordered $\gamma^{\prime}$-precipitates. The shearing of $\gamma^{\prime}$-precipitates occurred through an Anti-phase boundary (APB) mechanism by paired superlattice dislocations and or a Stacking Fault (SF) mechanism by partial dislocations. The fracture mode changed from the dimpled-ductile to brittle fracture after He implantation. Cross-sectional TEM examinations on focused ion beam (FIB) lift-out samples were performed to trace crack initiation/propagation sites to characterize the failure mechanisms, intergranular (see figure 2) or transgranular. Results show that grain boundary cracks form preferentially at the interface of chromium carbide perforated by an array of cavities. Cracks also occur within the grains that initiate at the interface of pre-existing twin/martensite platelets. 


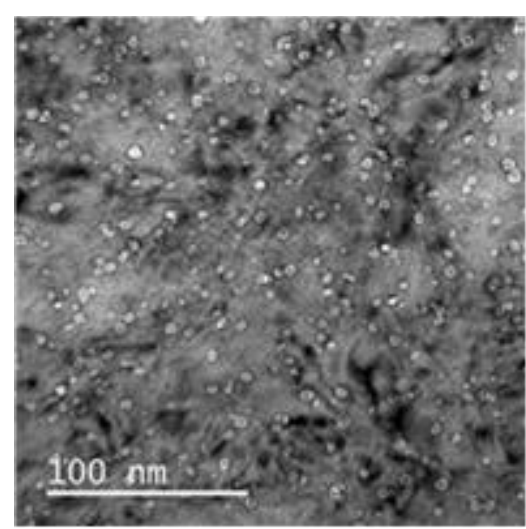

Figure 1. Figure 1. After helium ion implantation, the bright field micrograph showing the cavities.

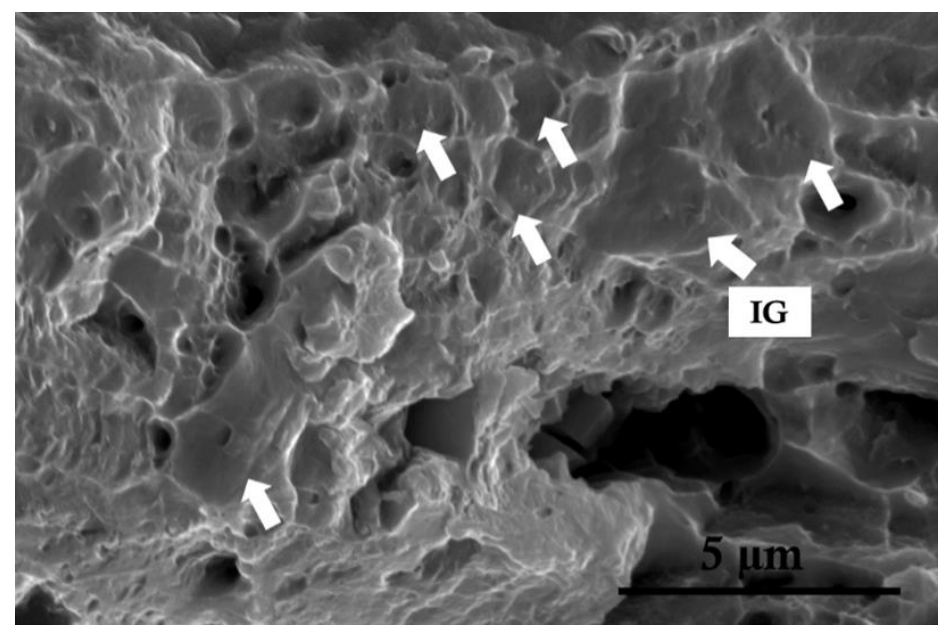

Figure 2. Fig. 2. The SEM fractography on helium-implanted sample shows the grain facets which indicate the intergranular fracture.

\section{References}

1. M. Griffiths, "The Effect of Irradiation on Ni-containing Components in CANDU Reactor Cores: A Review", AECL Nuclear Review, Vol. 2, No. 1, 1-16, 2013.

2. P Changizian, Z Yao, MR Daymond, 'Deformation mechanism characteristics in a Ni-based alloy X750: Dislocation/precipitate interaction' Materials Characterization 172, 110891, 2021. 